\title{
Effect of Silver Addition on the Ethanol-Sensing Properties of Indium Oxide Nanoparticle Layers: Optical Absorption Study
}

\author{
Vidya Nand Singh, ${ }^{1}$ Bodh Raj Mehta, ${ }^{1}$ Rakesh Kumar Joshi, ${ }^{2}$ and Frank Einar Kruis ${ }^{2}$ \\ ${ }^{1}$ Thin Film Laboratory, Department of Physics, Indian Institute of Technology Delhi, Hauz Khas, New Delhi 110016, India \\ ${ }^{2}$ Institute of Nanostructures and Technology, Faculty of Engineering Sciences, Campus Duisburg, \\ University Duisburg-Essen, Bismarckstr. 81, 47057 Duisburg, Germany
}

Received 21 December 2006; Accepted 11 March 2007

Recommended by Masamichi Yoshimura

$\mathrm{In}_{2} \mathrm{O}_{3}$ and $\mathrm{In}_{2} \mathrm{O}_{3}$ :Ag nanoparticle layers have been deposited using a two-step method consisting of chemical capping and dip coating techniques. The result of optical absorption analysis of $\operatorname{In}_{2} \mathrm{O}_{3}: \mathrm{Ag}$ samples shows the presence of $\mathrm{Ag}_{2} \mathrm{O}$ and Ag in air-annealed and vacuum-annealed samples, respectively. These results have been correlated with the gas sensing properties of these layers towards ethanol and support the proposed mechanism that increase in sensor response on Ag addition is due to the conversion of $\mathrm{Ag}_{2} \mathrm{O}$ to $\mathrm{Ag}$ in the presence of ethanol.

Copyright ( $) 2007$ Vidya Nand Singh et al. This is an open access article distributed under the Creative Commons Attribution License, which permits unrestricted use, distribution, and reproduction in any medium, provided the original work is properly cited.

\section{INTRODUCTION}

Recently, gas-sensing properties of oxide semiconductors have been improved by preparing these materials in nanocrystalline or nanoparticle forms [1]. The sensing mechanism is based on the fact that the adsorption of oxygen on the semiconductor surface causes a significant change in the electrical resistance of the material. The formation of oxygen adsorbate $\left(\mathrm{O}^{-2}\right.$ or $\left.\mathrm{O}^{-}\right)$results in an electrondepletion surface layer due to electron transfer from the oxide surface to oxygen. The sensing properties of oxide semiconductor materials also have been modified by adding metals or metal oxides as catalytic activator [2]. The effect of metal/metal oxide addition on gas-sensing phenomenon of oxide semiconductor has been explained in terms of doping of oxide matrix by metal atoms or formation of nano, micro, or macro-agglomerated metal clusters [3]. Various possible mechanisms have been suggested for the enhanced gas-sensing properties in presence of metal/metal oxide. In almost all studies, the structure of the metal nanoparticles in the composite nanoparticles is not well defined. In the present study, $\mathrm{In}_{2} \mathrm{O}_{3}$ :Ag composite nanoparticle layers have been synthesized by a two-step synthesis process using chemically grown $\mathrm{In}_{2} \mathrm{O}_{3}$ and $\mathrm{Ag}$ nanoparticles. Based on the detailed optical absorption studies, a possible mechanism for the effects of metal addition on the gas sensing properties has been suggested. Formation of nanoparticles and layers in two separate steps provides the advantage of controlling the individual nanoparticle size, composition, and film thickness independently.

\section{EXPERIMENTAL}

Synthesis of $\mathrm{In}_{2} \mathrm{O}_{3}$ and $\mathrm{Ag}$ nanoparticles has been carried out by chemical capping method as discussed earlier [47]. The $\operatorname{In}(\mathrm{OH})_{3}$ nanoparticles were synthesized by heating $0.01 \mathrm{M} \mathrm{InCl}_{3} \cdot 3 \mathrm{H}_{2} \mathrm{O}$ in ethanol and $0.01 \mathrm{M}$ alanine in ammonia solutions (in a ratio of $1: 2.5$ ) at $80^{\circ} \mathrm{C}$ for 20 hours with continuous stirring. The nanoparticles were collected and washed several times using deionised water to remove the excess ions. This is followed by vacuum drying. $\mathrm{In}_{2} \mathrm{O}_{3}$ nanoparticles were prepared by heating $\operatorname{In}(\mathrm{OH})_{3}$ nanoparticles at $350^{\circ} \mathrm{C}$. For the synthesis of $\mathrm{Ag}$ nanoparticles, PVP, poly (N-vinyl-2-pyrrolidone) and silver perchlorate were heated in ethanol/water mixture at $90^{\circ} \mathrm{C}$ with continuous stirring. Silver nanoparticles were obtained after centrifugation. $\mathrm{In}_{2} \mathrm{O}_{3}$ :Ag (IAG15) composite nanoparticle layers with 15 weight $\%$ Ag were prepared by a dip-coating method. The required amount of precursor nanoparticles, $\mathrm{In}_{2} \mathrm{O}_{3}$ and Ag were dispersed in ethanol. The deposited layers were dried at a temperature of $100-120^{\circ} \mathrm{C}$ for few minutes to evaporate out the solvents after each dip. 
Glancing angle X-ray diffraction (GAXRD) analysis of nanoparticle layers was obtained using Rigaku diffractometer (Giegerflex-D/max-RB-Ru 200). A Philips CM12 electron microscope was used for transmission electron microscopy (TEM) studies. Nanoparticles were dispersed ultrasonically in water and spread over formvar coated copper grids for TEM analysis. For gas-sensing measurements, the dispersed nanoparticles were spread on substrates with interdigitated electrodes by carefully placing drops onto the substrate followed by drying in an oven at $100^{\circ} \mathrm{C}$, as described elsewhere $[5,6]$. Specially designed buried electrodes have been used for maintaining the homogeneity and uniformity of the nanoparticle layers. The structures are bonded to a DIL16 chip carrier through gold bond wires. A poly-Si layer, which is embedded in the structure to serve as the heating element, allows a maximum surface temperature of $300^{\circ} \mathrm{C}$. An external heating arrangement has been used in order to heat the substrate to higher temperatures. A temperaturedependent resistor close to the interdigitated electrodes allows the temperature measurement. The gas-sensing properties in terms of sensor response and response time were determined by measuring the time-dependent changes in resistance on changing the gas environment in the measurement cell in the temperature range of $100-400^{\circ} \mathrm{C}$.

\section{RESULT AND DISCUSSION}

GAXRD spectrum of composite nanoparticle layer sample IAG15 annealed at $400^{\circ} \mathrm{C}$ for 90 minutes is shown in Figure 1(a). The most intense peak observed in the GAXRD spectrum at $2 \theta=30.6^{\circ}$ belongs to (222) plane of cubic $\mathrm{In}_{2} \mathrm{O}_{3}$. The XRD spectra of nanoparticle samples $\mathrm{Ag}$ and $\mathrm{In}_{2} \mathrm{O}_{3}$ annealed at $400^{\circ} \mathrm{C}$ for 90 minutes are shown in (b) and (c) of Figure 1, respectively. The broadening of the FWHM is due to the absence of long-range order because of the finite size of nanoparticles. TEM micrographs of samples IAG15 annealed at $400^{\circ} \mathrm{C}$ are shown in Figure 2. The average size of $\mathrm{In}_{2} \mathrm{O}_{3}$ and $\mathrm{Ag}$ nanoparticles is $13 \mathrm{~nm}$ and $14 \mathrm{~nm}$, respectively. In the micrograph of IAG15 nanoparticle layers, the dispersion of $\mathrm{Ag} / \mathrm{Ag}_{2} \mathrm{O}$ nanoparticles (relatively darker spots) in a network of indium oxide nanoparticles (less dark spots) has been marked.

Optical absorption spectra of nanoparticle layers samples $\mathrm{In}_{2} \mathrm{O}_{3}, \mathrm{Ag}$, and IAG15 are shown in Figure 3. The optical absorption spectrum of $\operatorname{In}_{2} \mathrm{O}_{3}$ sample shows a band edge at $305 \mathrm{~nm}$ characteristics of $\mathrm{In}_{2} \mathrm{O}_{3}$ nanoparticles. Spectrum of Ag sample shows a surface plasmon resonance peak at $430 \mathrm{~nm}$ characteristics of silver nanoparticles dispersed in PVP matrix. In the optical absorption spectrum of IAG15, both the features corresponding to $\operatorname{In}_{2} \mathrm{O}_{3}$ and the surface plasmon peak corresponding to $\mathrm{Ag}$ has been observed. The intensity of the absorption edge corresponding to $\operatorname{In}_{2} \mathrm{O}_{3}$ and surface plasmon resonance peak corresponding to $\mathrm{Ag}$ are proportional to the composition used.

The optical absorption spectrum of the IAG15 samples as-synthesized, annealed in air at $200^{\circ} \mathrm{C}, 300^{\circ} \mathrm{C}$, and $400^{\circ} \mathrm{C}$ for 90 minutes are shown in Figure 4. The optical absorbance spectra for as-synthesized IAG15 consist of a band edge at

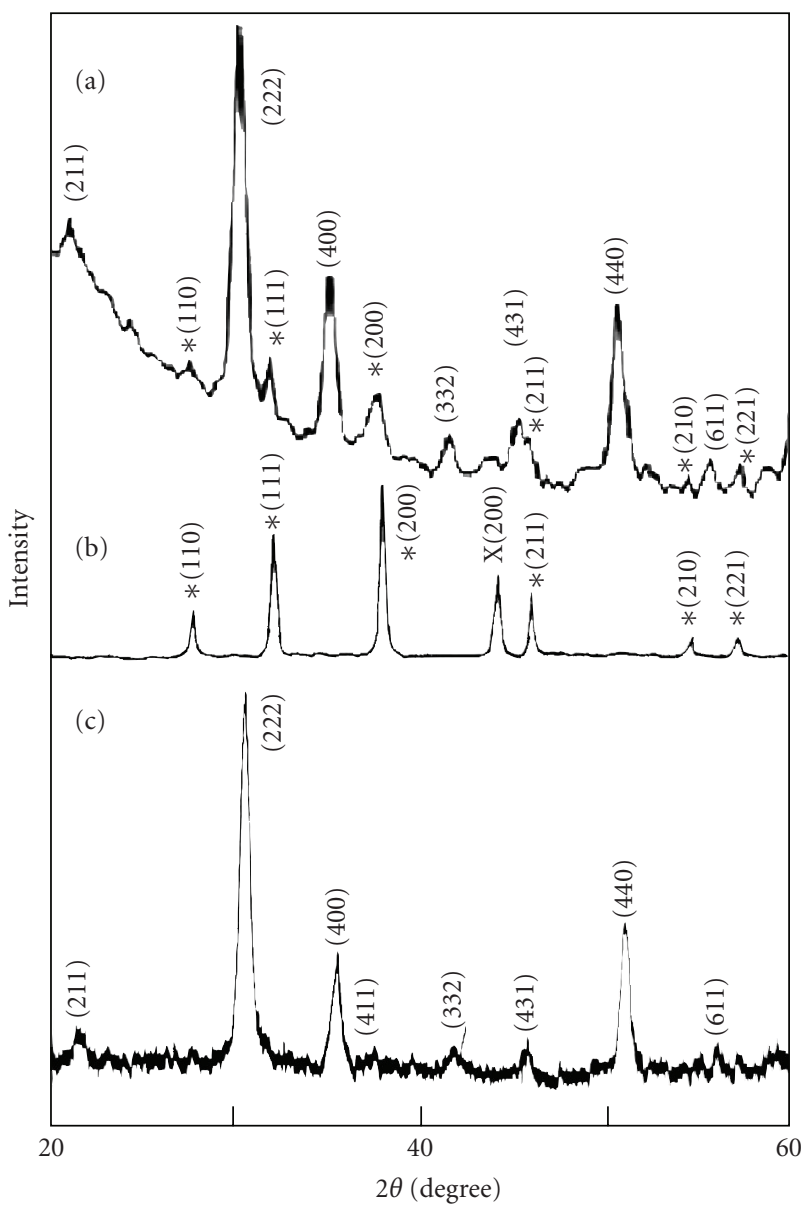

FIGURE 1: (a) GAXRD spectrum of sample IAG15, XRD spectra of (b) Ag nanoparticles sample and (c) $\mathrm{In}_{2} \mathrm{O}_{3}$ nanoparticles sample. All samples are annealed at $400^{\circ} \mathrm{C}$ for 90 minutes. $(*)$ shows the peaks corresponding to the cubic $\mathrm{Ag}_{2} \mathrm{O}$ phase and (X) shows the peaks corresponding to cubic Ag phase.

$300 \mathrm{~nm}$ corresponding to $\operatorname{In}_{2} \mathrm{O}_{3}$ nanoparticles and a surface plasmon resonance (SPR) peak at $430 \mathrm{~nm}$ corresponding to silver nanoparticles. For samples annealed at $200^{\circ} \mathrm{C}$, the intensity of the SPR peak decreases drastically along with the broadening of the peak. For the samples annealed at $300^{\circ} \mathrm{C}$ and $400^{\circ} \mathrm{C}$, the peak disappears. This may be due to the conversion of $\mathrm{Ag}$ nanoparticles to $\mathrm{Ag}_{2} \mathrm{O}$ nanoparticles and is consistence with the GAXRD results. It has been reported that due to a small size and increased surface to volume ratio, Ag nanoparticles have higher reactivity and they convert to $\mathrm{Ag}_{2} \mathrm{O}$ at a temperature of $300^{\circ} \mathrm{C}$ in air [8]. The optical absorption spectra of the IAG15 samples annealed in vacuum at $200^{\circ} \mathrm{C}, 300^{\circ} \mathrm{C}$, and $400^{\circ} \mathrm{C}$ for 90 minutes are shown in Figure 5. The optical absorbance spectra for samples IAG15 annealed at $200^{\circ} \mathrm{C}$ consists of a band edge at $300 \mathrm{~nm}$ corresponding to $\mathrm{In}_{2} \mathrm{O}_{3}$ nanoparticles and a surface plasmon resonance (SPR) peak at $430 \mathrm{~nm}$ corresponding to silver nanoparticles. For samples annealed at $300^{\circ} \mathrm{C}$ and $400^{\circ} \mathrm{C}$, the intensity of the SPR peak decreases. In case of vacuum-annealed samples, $\mathrm{Ag}$ is still present and it has not 


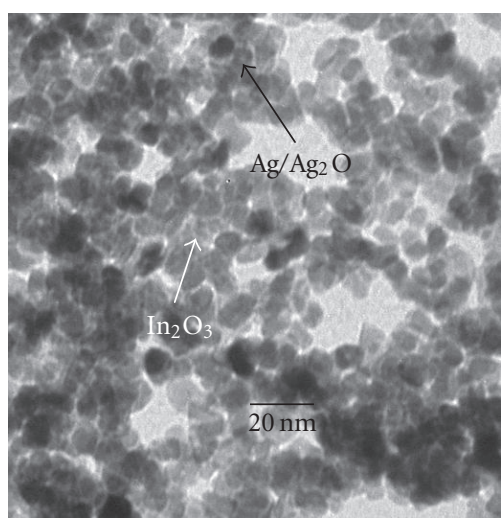

FIGURE 2: TEM micrograph of IAG15 nanoparticle layer sample annealed at $400^{\circ} \mathrm{C}$ for 90 minutes. The $\mathrm{In}_{2} \mathrm{O}_{3}$ as well as the $\mathrm{Ag}_{2} \mathrm{O}$ nanoparticles are marked.

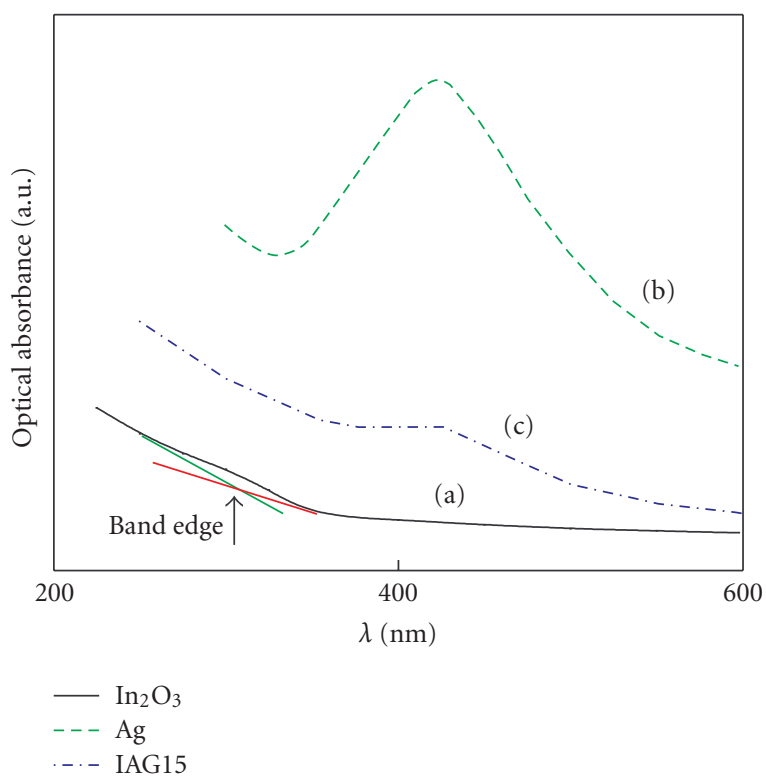

Figure 3: Optical absorbance spectra of the nanoparticle samples (a) $\mathrm{In}_{2} \mathrm{O}_{3}$, (b) Ag, and (c) IAG15.

completely converted to $\mathrm{Ag}_{2} \mathrm{O}$. Thus, upon annealing in air at $200^{\circ} \mathrm{C}$ to $400^{\circ} \mathrm{C}$, the nanoparticle layers exist as $\mathrm{In}_{2} \mathrm{O}_{3}: \mathrm{Ag}_{2} \mathrm{O}$ and in the case of vacuum annealing they exist mainly as $\mathrm{In}_{2} \mathrm{O}_{3}$ :Ag. The optical study has been found to be reversible and reproducible.

Figure 6 shows a comparison of the sensor response and the response time for the $\operatorname{In}_{2} \mathrm{O}_{3}$ and $\mathrm{In}_{2} \mathrm{O}_{3}$ : $\mathrm{Ag}$ nanoparticle layers at $400^{\circ} \mathrm{C}$ for $1000 \mathrm{ppm}$ ethanol. Figure 7 shows a typical sensor response for composite nanoparticle layer. Sensor response is the ratio of the conductance of the nanoparticle layer in ethanol in synthetic air to the conductance in

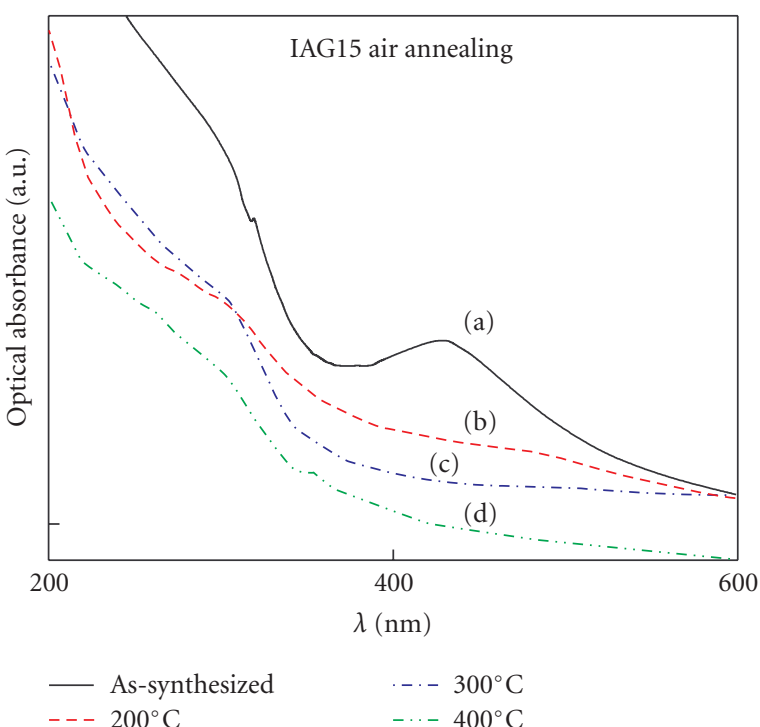

FIGURE 4: Optical absorbance spectra of the IAG15 composite nanoparticle layers (a) as-synthesized, annealed in air at (b) $200^{\circ} \mathrm{C}$, (c) $300^{\circ} \mathrm{C}$, and (d) $400^{\circ} \mathrm{C}$ for 90 minutes.

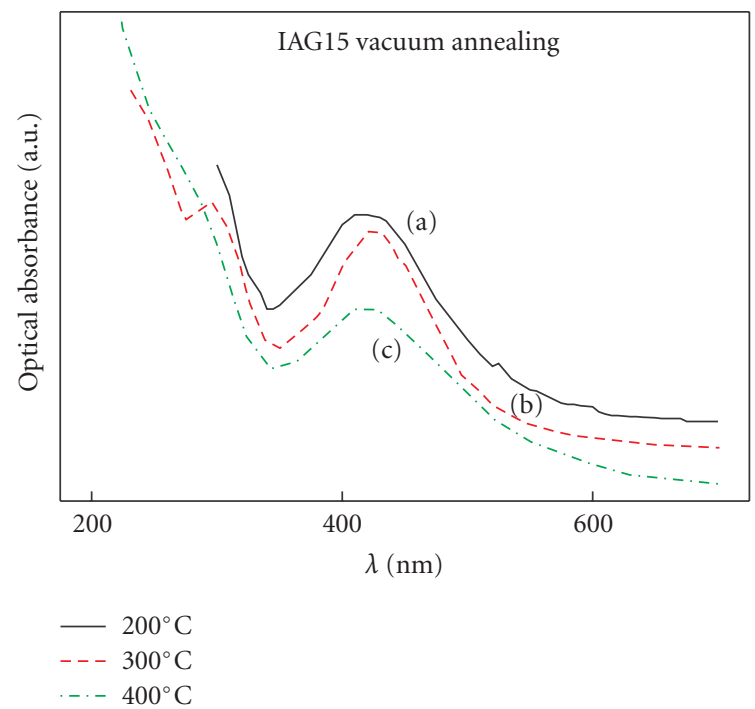

FIGURE 5: Optical absorbance spectra of the IAG15 composite nanoparticle layers annealed in vacuum at (a) $200^{\circ} \mathrm{C}$, (b) $300^{\circ} \mathrm{C}$, and (c) $400^{\circ} \mathrm{C}$ for 90 minutes.

synthetic air. Response time is the time required in reaching $70 \%$ of the saturated value of resistance in presence of ethanol. The sensor response in the case of IAG15 increases to 436 and the response time is about 6 seconds as compared to a sensor response of 325 and a response time of 8 seconds for $\mathrm{In}_{2} \mathrm{O}_{3}$ nanoparticle layers.

As discussed earlier, air-annealed $\mathrm{In}_{2} \mathrm{O}_{3}$ :Ag nanoparticle layers exist as $\mathrm{In}_{2} \mathrm{O}_{3}: \mathrm{Ag}_{2} \mathrm{O}$ and in vacuum-annealed samples, they exist mainly as $\mathrm{In}_{2} \mathrm{O}_{3}$ :Ag. It is expected that the effect of exposure to ethanol vapours will be similar to annealing in vacuum. Increased gas-sensing response is thus linked with 


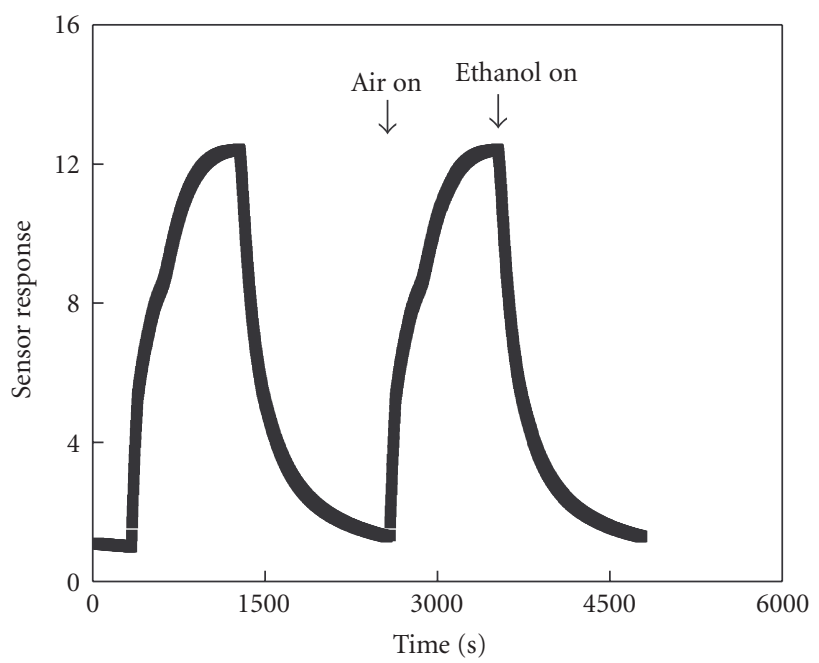

Figure 6: A representative gas-sensing response curve obtained with sample IAG15 for $10 \mathrm{ppm}$ ethanol.

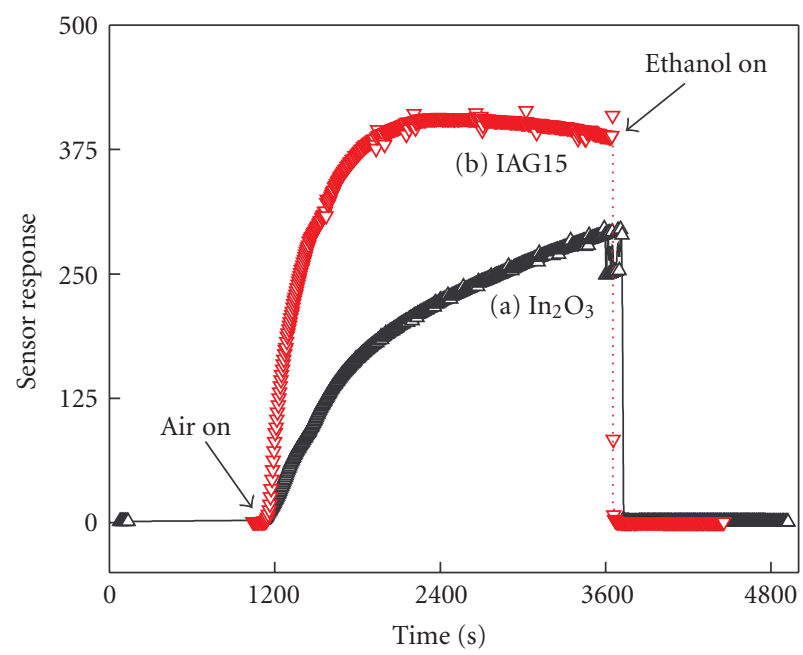

FIgURE 7: Comparison of the ethanol-sensing behavior of $\operatorname{In}_{2} \mathrm{O}_{3}$ and IAG15 nanoparticle layers for $1000 \mathrm{ppm}$ ethanol at $400^{\circ} \mathrm{C}$.

the transformation of depletion layer in case of $\mathrm{Ag}_{2} \mathrm{O}-\mathrm{In}_{2} \mathrm{O}_{3}$ interface to an accumulation layer in case of $\mathrm{Ag}-\mathrm{In}_{2} \mathrm{O}_{3}$ as schematically described in Figure 8 [9]. This explains the high sensor response to ethanol in presence of Ag. In case of an $\mathrm{In}_{2} \mathrm{O}_{3}$ layer without $\mathrm{Ag}$ addition, gas-sensing response depends on the degree of depletion of electrons from $\operatorname{In}_{2} \mathrm{O}_{3}$ by adsorbed oxygen and the effectiveness of removal of oxygen species by ethanol. In case of $\mathrm{In}_{2} \mathrm{O}_{3}$ having appropriate amount of $\mathrm{Ag}$, gas-sensing response depends upon the effectiveness of reduction of $\mathrm{Ag}_{2} \mathrm{O}$ to $\mathrm{Ag}$ in the presence of reducing ambient (ethanol). The resistance in air and in $1000 \mathrm{ppm}$ ethanol for the $\mathrm{In}_{2} \mathrm{O}_{3}$ and for IAG15 nanoparticle layers is $550 \mathrm{~K} \mathrm{Ohms,} 350 \mathrm{~K}$ Ohms, $1.21 \mathrm{~K} \mathrm{Ohms,} \mathrm{and}$ $0.820 \mathrm{~K}$ Ohms, respectively. As the gas sensing mechanism is based on the interaction of sensing gas with Ag, use of Ag nanoparticles is advantageous as it provides a large

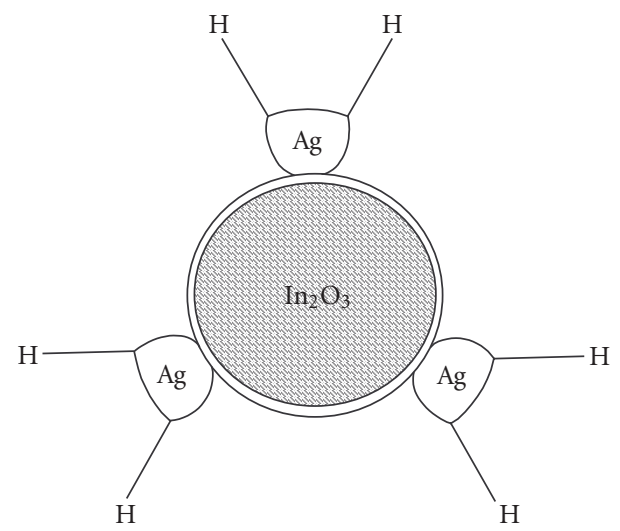

(a)

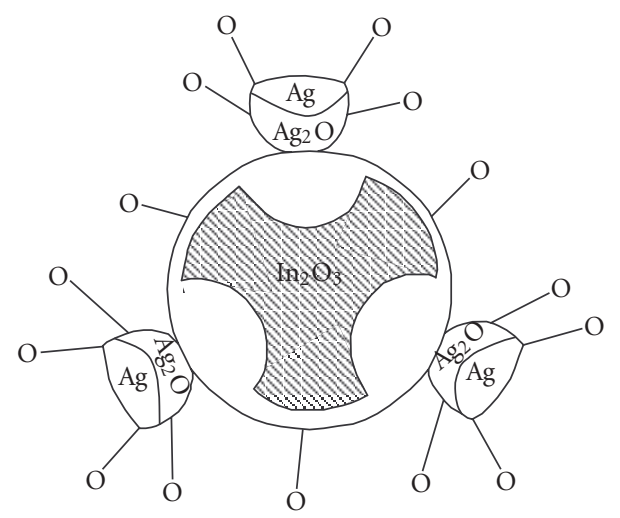

(b)

FIgURE 8: A schematic diagram showing electronic interaction at (a) $\mathrm{In}_{2} \mathrm{O}_{3}: \mathrm{Ag}$ and (b) $\mathrm{In}_{2} \mathrm{O}_{3}: \mathrm{Ag}_{2} \mathrm{O}$ nanoparticle interfaces. In presence of ethanol, $\mathrm{Ag}_{2} \mathrm{O}$ converts to $\mathrm{Ag}$, the electron-depletion surface layer of $\operatorname{In}_{2} \mathrm{O}_{3}$ becomes smaller due to release of the electrons to $\operatorname{In}_{2} \mathrm{O}_{3}$, and thus the conductivity gets enhanced. In air, electron-depletion surface layer gets enhanced due to electron transfer to oxygen as well as to $\mathrm{Ag}_{2} \mathrm{O}$ from $\mathrm{In}_{2} \mathrm{O}_{3}$.

surface area for interaction with the sensing gas. Size of $\operatorname{In}_{2} \mathrm{O}_{3}$ nanoparticles $(13 \mathrm{~nm})$ used in the present study falls in the range of Debye length values estimated for oxide semiconductors $[10,11]$. The nanoparticle size used is thus quite optimum for high sensor response. Use of $\mathrm{Ag}$ and $\mathrm{In}_{2} \mathrm{O}_{3}$ nanoparticles of approximately equal sizes is expected to result in homogenous mixing of two phases in composite nanoparticle samples. Our earlier studies have shown that particle size, structure, and the properties of the nanoparticles do not change at the operating temperature used in the present study $[4,5]$. Papadopoulos et al. have reported a sensor response of 33 in $\mathrm{In}_{2} \mathrm{O}_{3}$ films for $26 \mathrm{ppm}$ ethanol at $450^{\circ} \mathrm{C}$ [12]. Shukla et al. have reported a sensor response value of 16 for $1000 \mathrm{ppm}_{2}$ at $50^{\circ} \mathrm{C}$ [1]. Chung et al. have reported sensor response of 88 for $2000 \mathrm{ppm}$ ethanol at $350^{\circ} \mathrm{C}$ [13]. The high value of sensor response and faster response 
observed in the present study in comparison to the reported values in various oxide semiconductors (especially, sensing response towards reducing gases) can thus be directly correlated with the electronic interaction, larger surface area due to nanoparticle nature of both the phases used in the present study.

\section{CONCLUSIONS}

$\mathrm{In}_{2} \mathrm{O}_{3}$ and $\mathrm{In}_{2} \mathrm{O}_{3}$ :Ag nanoparticle layers having well-defined particle size and composition have been prepared using a two-step synthesis method. Optical absorption studies carried out on $\mathrm{In}_{2} \mathrm{O}_{3}$ :Ag samples show the presence of $\operatorname{In}_{2} \mathrm{O}_{3}$ and $\mathrm{Ag}_{2} \mathrm{O}$ phases in air-annealed samples. In vacuumannealed samples the presence of surface plasmon resonance peak shows the conversion of $\mathrm{Ag}_{2} \mathrm{O}$ to $\mathrm{Ag}$ phase. These results support the proposed mechanism based on the conversion of $\mathrm{In}_{2} \mathrm{O}_{3}: \mathrm{Ag}_{2} \mathrm{O}$ interface to $\mathrm{In}_{2} \mathrm{O}_{3}: \mathrm{Ag}$ interface on exposure to reducing gases and explain the enhance gas sensing properties of composite nanoparticle layers.

\section{ACKNOWLEDGEMENT}

This work was supported by Council for Scientific and Industrial Research (CSIR), New Delhi, India, under Grant no. 03(0995)/04/EMR-II.

\section{REFERENCES}

[1] S. Shukla, S. Seal, L. Ludwig, and C. Parish, "Nanocrystalline indium oxide-doped tin oxide thin film as low temperature hydrogen sensor," Sensors and Actuators B: Chemical, vol. 97, no. 2-3, pp. 256-265, 2004.

[2] G. Neri, A. Bonavita, G. Rizzo, S. Galvagno, N. Donato, and L. S. Caputi, "A study of water influence on CO response on golddoped iron oxide sensors," Sensors and Actuators B: Chemical, vol. 101, no. 1-2, pp. 90-96, 2004.

[3] A. Cabot, A. Diéguez, A. Romano-Rodríguez, J. R. Morante, and N. Bârsan, "Influence of the catalytic introduction procedure on the nano- $\mathrm{SnO}_{2}$ gas sensor performances: where and how stay the catalytic atoms?" Sensors and Actuators B: Chemical, vol. 79, no. 2-3, pp. 98-106, 2001.

[4] V. N. Singh and B. R. Mehta, "Nanoparticle size-dependent lowering of temperature for phase transition from $\operatorname{In}(\mathrm{OH})_{3}$ to $\mathrm{In}_{2} \mathrm{O}_{3}$," Journal of Nanoscience and Nanotechnology, vol. 5, no. 3, pp. 431-435, 2005.

[5] B. R. Mehta and V. N. Singh, "Structural, electrical and gassensing properties of $\operatorname{In}_{2} \mathrm{O}_{3}$ :Ag composite nanoparticle layers," Pramana - Journal of Physics, vol. 65, no. 5, pp. 949-958, 2005.

[6] V. N. Singh, B. R. Mehta, R. K. Joshi, F. E. Kruis, and S. M. Shivaprasad, "Enhanced gas sensing properties of $\operatorname{In}_{2} \mathrm{O}_{3}: \mathrm{Ag}$ composite nanoparticle layers; electronic interaction, size and surface induced effects," to appear in Sensors and Actuators B: Chemical, In Press.

[7] V. N. Singh, B. R. Mehta, R. K. Joshi, and F. E. Kruis, "Size-dependent gas sensing properties of indium oxide nanoparticle layers," Journal of Nanoscience and Nanotechnology, vol. 7, no. 7, 2007.

[8] U. K. Barik, S. Srinivasan, C. L. Nagendra, and A. Subrahmanyam, "Electrical and optical properties of reactive DC magnetron sputtered silver oxide thin films: role of oxygen," Thin Solid Films, vol. 429, no. 1-2, pp. 129-134, 2003.

[9] N. Yamazoe, "New approaches for improving semiconductor gas sensors," Sensors and Actuators B: Chemical, vol. 5, no. 1-4, pp. 7-19, 1991.

[10] N.-L. Wu, S.-Y. Wang, and I. A. Rusakova, "Inhibition of crystallite growth in the sol-gel synthesis of nanocrystalline metal oxides," Science, vol. 285, no. 5432, pp. 1375-1377, 1999.

[11] H. Ogawa, A. Abe, M. Nishikawa, and S. Hayakawa, "Preparation of tin oxide films from ultrafine particles," Journal of the Electrochemical Society, vol. 128, no. 3, pp. 685-689, 1981.

[12] C. A. Papadopoulos, D. S. Vlachos, and J. N. Avaritsiotis, "Comparative study of various metal-oxide-based gas-sensor architectures," Sensors and Actuators B: Chemical, vol. 32, no. 1, pp. 61-69, 1996.

[13] W.-Y. Chung, G. Sakai, K. Shimanoe, N. Miura, D.-D. Lee, and N. Yamazoe, "Preparation of indium oxide thin film by spincoating method and its gas-sensing properties," Sensors and Actuators B: Chemical, vol. 46, no. 2, pp. 139-145, 1998. 

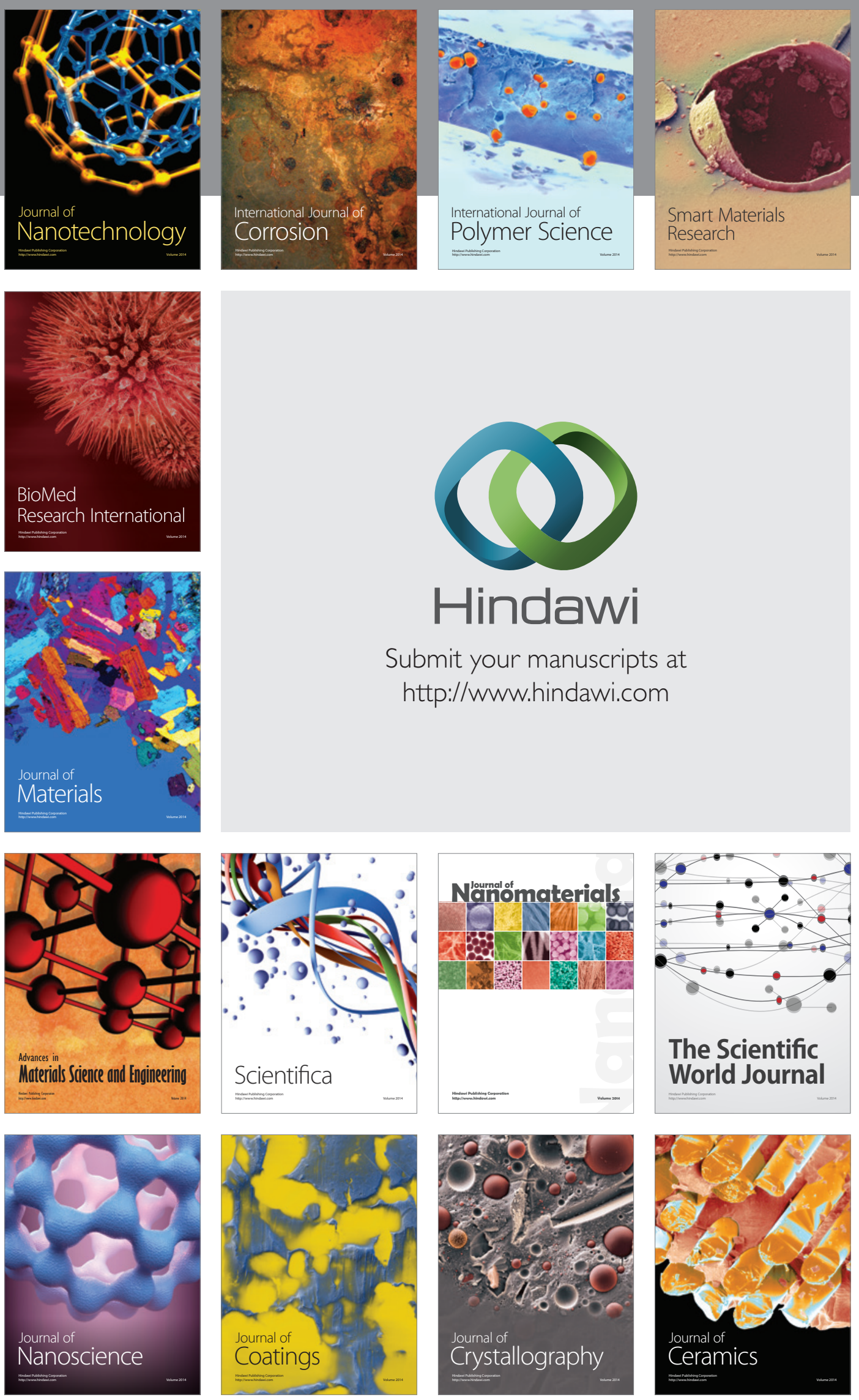

The Scientific World Journal

Submit your manuscripts at

http://www.hindawi.com

\section{World Journal}

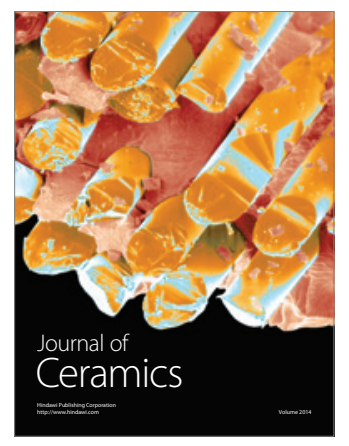

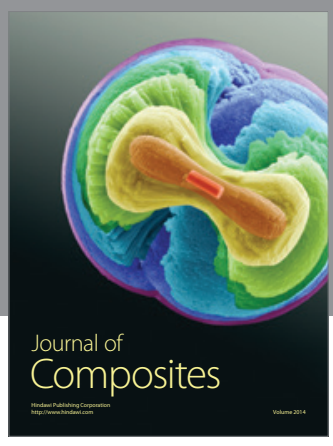
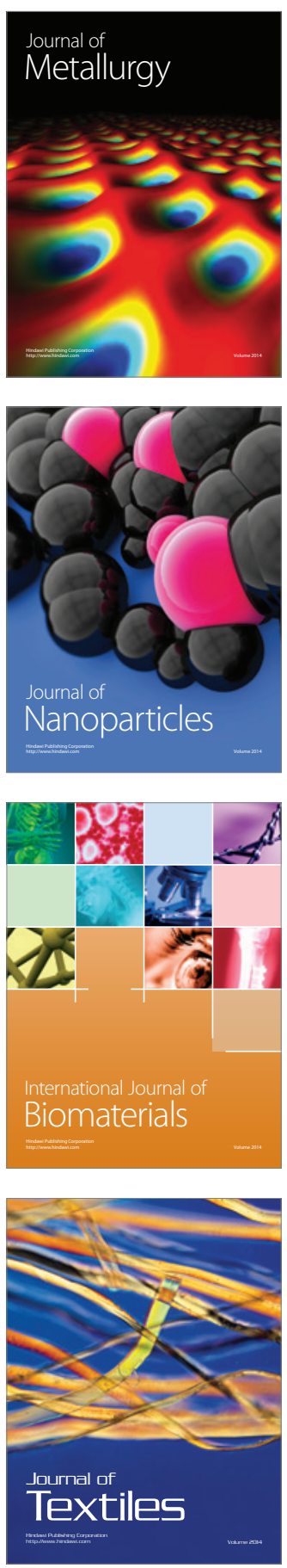